\title{
Proposal of an alternative concept of the manually adjustable hospital bed for user experience improvement
}

\author{
Diego Santos Duarte ${ }^{a}$ (D), Ricardo Manfredi Naveiro ${ }^{b}$ \\ - Programa Francisco Eduardo Mourão Saboya de Pós-Graduação em Engenharia Mecânica, Universidade Federal Fluminense - UFF, Niterói, RJ, Brasil \\ b Programa de Engenharia de Producçao, Instituto Alberto Luiz Coimbra de Pós-graduação e Pesquisa de Engenharia - COPPE, \\ Universidade Federal do Rio de Janeiro - UFRJ, Rio de Janeiro, RJ, Brasil \\ e-mails: diegodsd@poli.ufri.br; rnaveiro@poli.ufri.br
}

\begin{abstract}
Hospital beds that provide a good user experience interface are generally composed of electric-automated devices which substantially increase the final cost. In contrast, the most affordable versions are typically the manually adjustable beds, which do not currently provide soft and practical usage experience. In this sense, this paper aims to propose an alternative concept of the manually adjustable hospital bed that enhances the user experience while keeping its affordability. The product development process was based on a literature combination methodology, including the informational and conceptual phases. The informational stage runs through state-of-the-art reviews, usage experiencing and observation, user interviews and analytical QFD (Quality Functional Deployment) tools, leading to the conceptual stage with functional decomposition and morphological matrix. The final bed concept, proposed via CAD software and depicted into each feature-requirement correlation, comprises an innovative approach that soften the manual actuation. Industrialization of the proposal would assist customers with severe income restrictions.
\end{abstract}

Keywords: product development, manual hospital bed, QFD.

\section{Introduction}

\subsection{Motivation}

Hospital bed designs are elements of patient's interest, but it also encompasses relevant requirements from the individuals that will actually actuate the adjustments, such as the healthcare professionals and patient companies. As notably known, other stakeholders have additional product requirements, such as cost and manufacturability. Meeting all requirement needs special efforts mainly regarding the tradeoffs (Cheng \& Melo Filho, 2010). While the electric-automated and hydraulic beds notoriously attend the final users' requirements regarding practical and ergonomic adjustments, they have higher initial and maintenance costs compared to the manual versions and may represent impracticable options for income restricted customers.

\subsection{Aims and methodology}

Motivated by the current limitations cited above, the objective of this study is to propose an alternative concept for the manually adjustable hospital bed that provides all basic and safety requirements, but especially softens the manual actuation user experience and continues to represent a financially strategic option for costumers with limited budget.

The manual hospital bed is so called because of its adjustment mechanism, typically located beneath the bed stage at the foot of the bed. Hand cranks are the current manual actuators for adjustment of the bed height and backrest or thigh-rest angulations. Initially, the demand of this redesign project is basically to improve the user experience. For focusing purposes, the manual hospital bed was defined as the structure that supports the mattress, excluding it from the analysis.

This study is guided by product design processes based on general engineering (Ulrich \& Eppinger, 1995) and mechanical design (Ullman, 1992). A combined methodology from these authors is structured on Table 1 . In section 2 of this paper, a literature review introduces techniques and technical information used as a background knowledge. Section 3 encompasses the informational project, followed by the conceptual project in Section 4 . The results are presented through a product concept proposal via CAD software in Section 5. Finally, conclusions are discussed on Section 6. 
Table 1. Combined methodology for product development process.

\begin{tabular}{|c|c|c|}
\hline Project & Phase & Steps \\
\hline \multirow{7}{*}{ Informational } & \multirow{3}{*}{ Understanding } & Demand and target-user definition \\
\hline & & Existing solution review \\
\hline & & Requirement and constraint survey \\
\hline & \multirow{4}{*}{ Analysis } & Requirement \& specification gathering \\
\hline & & Requirement relevance \\
\hline & & Specification relevance \\
\hline & & Demand refinement \\
\hline \multirow{4}{*}{ Conceptual } & \multirow{4}{*}{ Conception } & Functional decomposition \\
\hline & & Solution generation following function \\
\hline & & Concept selection \\
\hline & & Product architecture \& Final concept \\
\hline
\end{tabular}

\section{Literature review}

The literature review in this study concerns to characterize the informational project by the investigation through the context wherein the product is inserted, as well as supporting techniques.

\subsection{Quality Function Deployment (QFD)}

According to Naveiro \& Oliveira (2018), "QFD is used to transform subjective user demands into objective parameters, leading to the identification of engineering characteristics which may be relevant, and assigning priorities for system requirements." This study utilizes QFD tools to collect, organize and evaluate data, enabling the refinement and convergence of the demand towards the real customer expectations. The tools used are the "Voice of Customer", for customer requirement assessment, and the Quality Matrix, for product specification assessment.

The user experience approach of this work follows a QFD tool denominated as the "Voice of Customer" (VOC). This approach is a fundamental assessment and should not only be restricted to passively interviewing and listening users, but also observing, playing their tasks and catching non-explicit factors. This task is classified as a qualitative survey, whose objective is to collect subliminal and meaningful data that will be quantitatively validated (Cheng \& Melo Filho, 2010). After collecting the data, a treatment is proposed to refine and validate information. Ullman (1992) says that the gathered requirements can be analyzed via a "Pairwise Comparison" or other internal methods by the design team. However, the present study considers appropriate to follow up with the VOC method (Cheng \& Melo Filho, 2010) that proposes a quantitative assessment, which customers evaluate requirements by giving relevance grades.

The product requirements summarize the collected data and represents "what" is expected from the product. Parallel to requirements, a product specification gathering translates the wishes into features, i.e. while requirements are "what" the product must have, the specifications are "how" to achieve these desires. From technical to aesthetic characteristics, specifications are generally concrete (Cheng \& Melo Filho, 2010). The specification relevance assessment utilizes all the data earlier processed in a Quality Matrix, also known as the "House of Quality", crossing the product requirements to its specifications, regarding their given relationship strengths and the requirement relevance grades from VOC assessment. Requirements are stated on the rows and specifications, on the columns of the matrix. The relationship strengths are input values inserted in each matrix cell, characterizing the level of relationship between the respective requirement and specification, being blank (not related), 1 (weak), 3 (moderated) or 9 (strong). Each specification will receive a score calculated through a weighted average - the sum of the input relationship strengths in its column weighted by the requirement grades. See the work of Cheng \& Melo Filho (2010) for more details regarding the Quality Matrix construction.

\subsection{State of the art}

Consulting pre-existing solution principles for the current problem is important for the product development process not only to comprehend what has already been designed, but also to support idea generation later on the process (Naveiro as cited in Romeiro Filho et al., 2009; Ullman, 1992; Ulrich \& Eppinger, 1995). This work considers reviewing intellectual property documents, academic projects and the most common beds offered by the market.

\subsection{Functional decomposition \& morphological matrix}

Decomposing the product's main function into subfunctions allows the design team to recognize each minimal desired aspect when coming up with solutions (Ullman, 1992; Ulrich \& Eppinger, 1995). Then, to organize idea generation in groups per subfunction, Ullman (1992) and Ulrich \& Eppinger (1995) recommend the 
morphological matrix as a support tool, which displays the solution principles for each of the stated subfunctions. At this stage, the divergent thinking is welcome, so that the state-of-the-art materials may help the design team perform a better brainstorm (Ullman, 1992; Ulrich \& Eppinger, 1995).

\subsection{Technical information on papers, guidelines and standards}

To properly orient the development process, Ullman (1992) and Ulrich \& Eppinger (1995) also recommend surveys about what specialists of the respective field of study have already concluded about the problem. In this work, two surveys were carried out: one aiming to comprehend the medical guidelines regarding the bed usage and the other to comprehend the Brazilian standards and regulations for manual hospital beds. These documents were searched on Google Scholar and on regulatory and standard agencies websites, restricted to the Boolean expression: "hospital" AND "bed". The results, that contributes to the requirement gathering of this study, in the past 40 years, are summarized on the following topics:

- Importance of Fowler and Trendelemburg positions to blood circulation and other symptoms (Correa \& Waldow, 1982);

- Bedsores are caused by pressure and friction combination on patient skin. Bedsores also increase risks of infections and may lead to secondary fatal injuries. The indicated prevention consists in changing patient decubitus every two hours (Brasil, 2013);

- Patient movement manipulation and transferring are the main reasons of loading occupational problems in nurses (Rodrigues et al., 2013). Special guidelines and supporting devices are presented by Alexandre \& Rogante (2000);

- Laguna-Parras et al. (2011) and Diccini et al. (2008) conducted hospital incident studies and detected patient fall occurrence due to side trails lowered;

- The need of agile medical proceedings is essential for patient's lives, e.g. in cardiopulmonary arrest, the brain death will occur after four to five minutes and the resuscitation maneuvers (CPR) are urgent, including intubation and cardiac massage (Victorelli et al., 2013);

- In Brazil, every health-related product has to be registered at Anvisa before manufacturing, commercialization or delivery to customers (Brasil, 2017);

- Safety, guidelines for testing and labeling and dimensional constraints to avoid accidents are discriminated in ABNT standard (Associação Brasileira de Normas Técnicas, 2013).

\section{Informational project}

The informational project starts with an understanding phase, followed by a data evaluation with QFD tools. Then, by knowing better the context and the most important product aspects, it is possible to propose a demand refinement, or even, a redefinition.

\subsection{Understanding phase}

This phase comprises initial claims and data gatherings to understand the problem. As mentioned, the initial demand is to improve the user experience with the manual hospital bed. The target users are defined as: patients, patient companies and healthcare professionals.

Regarding the state-of-the-art review described in Subsection 2.2, the hospital bed review was not only restrained to the manual version in order to reach as diverse principles as possible. For the market research, the sources were sale and manufacturer websites, most Brazilians, accounting eight different types of manual bed (Bond Hospitalar, 2018; Metahospitalar, 2018; Ortopedia Portugal, 2018). The academic research was driven focusing on Brazilian university projects, resulting in 4 documentations (Missio \& Mazzini Junior, 2016; Gomide et al., 2015; Silva Júnior, 2003; Malça \& Beirão, 2010). For intellectual property documents, two agencies were consulted "Instituto Nacional da Propriedade Industrial" (INPI) and "United States Patent and Trademark Office" (USPTO). From 71 inventions analyzed on INPI database, 9 were documented, against 26 out of 300 reviewed on USPTO. For all researches, repetitive patterns were documented only once. All research documentation is detailed on Figure 1 and Figure 2, separated by product components and functions, respectively. Consisting in a visualization tool, these figures facilitate the design team to quickly look at the collected principles at any time along the process. Table 2 indexes the intellectual property references (Instituto Nacional da Propriedade Intelectual, 2018; United States Patent and Trademark Office, 2018).

Then, regarding the user experience approach mentioned in Subsection 2.1, four healthcare centers were visited in the state of Rio de Janeiro, Brazil, to contact people from the target group.

\subsection{Analysis phase}

The outcomes of the user experience approach and literature review became product requirements and, sequentially, the product specifications were derived 


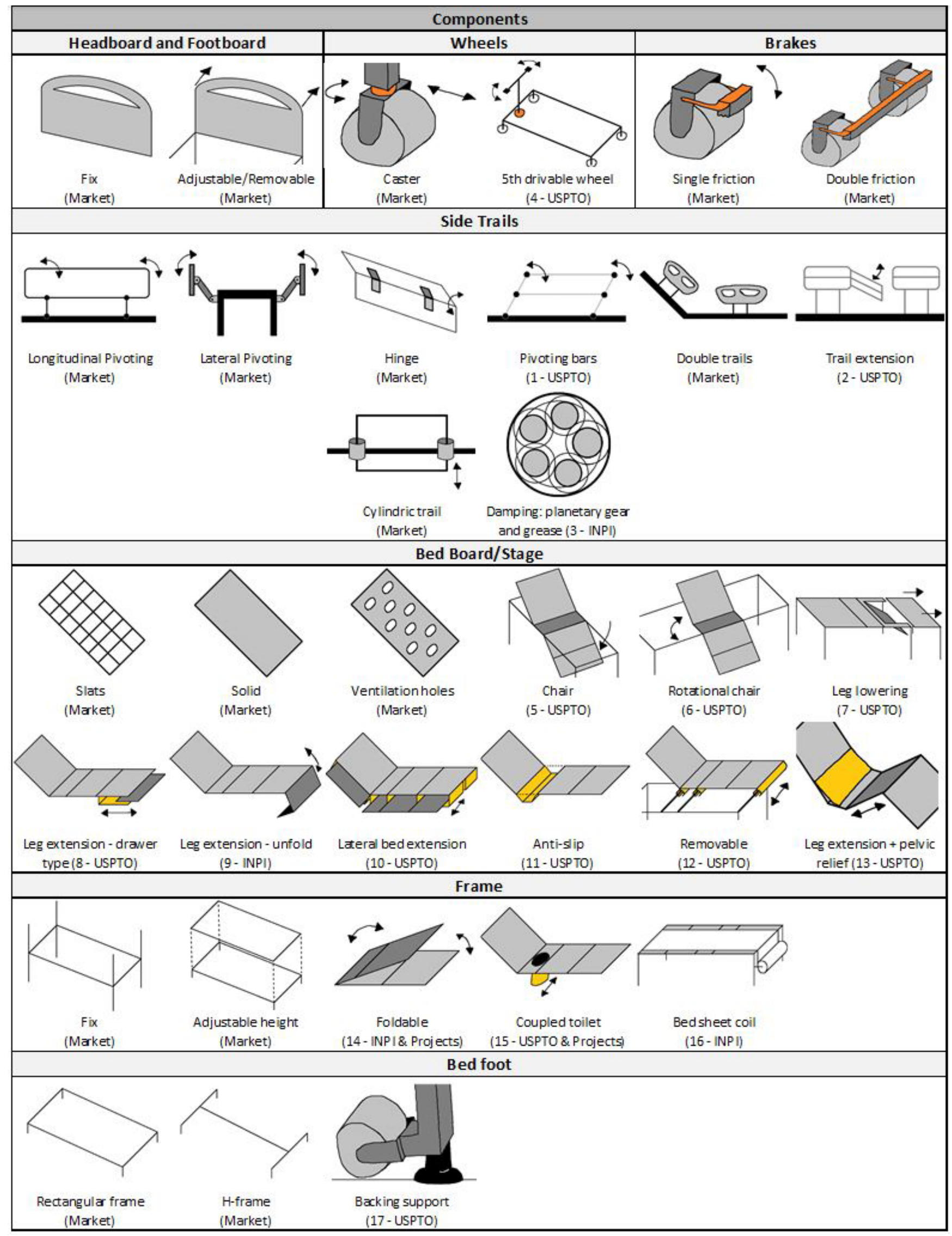

Figure 1. Research Documentation: hospital bed components. 


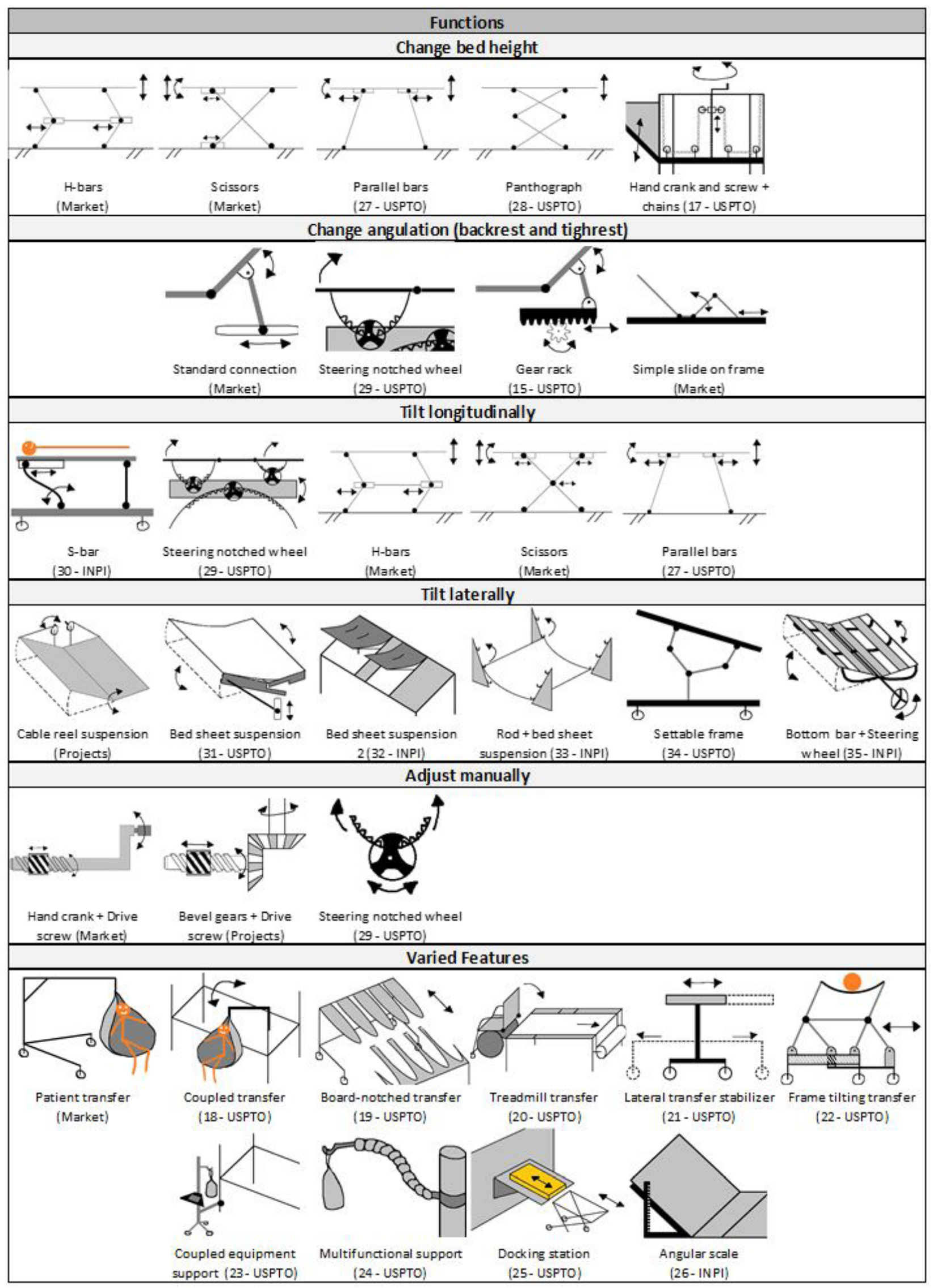

Figure 2. Research Documentation: hospital bed functions. 
Table 2. Intellectual Property Index (Instituto Nacional da Propriedade Intelectual, 2018; United States Patent and Trademark Office, 2018).

\begin{tabular}{|c|l|c|l|c|l|}
\hline Index & \multicolumn{1}{|c|}{ Document Code } & Index & \multicolumn{1}{|c|}{ Document Code } & Index & \multicolumn{1}{|c|}{ Document Code } \\
\hline 1 & US 8,001,631 B2 & 13 & US 2002/0178502 A1 & 25 & US 7,636,966 B2 \\
\hline 2 & US 5,381,571 A & 14 & BR 202014030357-5 U2 & 26 & BR PI 0400234-2 A \\
\hline 3 & BR 202013019424-2 U2 & 15 & US 8,510,881 B1 & 27 & US 9,855, 176 B2 \\
\hline 4 & US 7,311,161 B2 & 16 & BR MU 8200255-0 U & 28 & US 5,613,255 \\
\hline 5 & US 7,017,208 B2 & 17 & US 6,505,365 B1 & 29 & US 1,529,699 \\
\hline 6 & US 8,375,489 B2 & 18 & US 8,997,276 B2 & 30 & BR MU 7701524-0 U \\
\hline 7 & US 5,577,279 A & 19 & US 2007/0028381 A1 & 31 & US 2009/0013469 A1 \\
\hline 8 & US 3,220,022 & 20 & US 9,333,131 B2 & 32 & BR PI 0100713-0 A \\
\hline 9 & BR PI 0001436-2 A & 22 & US 7,562,403 B2 & 33 & BR MU 8702879-4 U2 \\
\hline 10 & US 8,104,122 B2 & 23 & US 8,056,162 B2 & 34 & US 8,950,026 B2 \\
\hline 11 & US 9,907,714 B2 & 24 & US 6,409,131 B1 & & BR MU 8901494-4 U2 \\
\hline 12 & US 2010/0313358 A1 & & & \\
\hline
\end{tabular}

Table 3. Customer Requirements and Product Specifications and respective indexes.

\begin{tabular}{|c|l|c|l|c|l|}
\hline \multicolumn{3}{|c|}{ Customer Requirements } & \multicolumn{5}{c|}{ Product Specifications } \\
\hline 1 & Perform Fowler position & 1 & Number of degree of freedom & 21 & Headboard Adj. Mechanism \\
\hline 2 & Perform Trendelemburg positions & 2 & Number of joints & 22 & Bed Stage Extension Mechanism \\
\hline 3 & Adjustments without huge efforts & 3 & Cost & 23 & Food Tray Coupling Mechanism \\
\hline 4 & Quick adjustments & 4 & Total Mass & 24 & Geometry/Shape of Wheels \\
\hline 5 & Comfortable actuation height & 5 & Required Force & 25 & Geometry/Shape of Frame Rods \\
\hline 6 & Angular adjustment indicator & 6 & Adjustment Velocity & 26 & Geometry/Shape of Side trails \\
\hline 7 & Equipment support (easy transportation) & 7 & Adj. Variation Amplitude & 27 & Geometry/Shape of Headboard \\
\hline 8 & Adjustable headboard & 8 & \# of steps for Adjustment & 28 & Geometry/Shape of Footboard \\
\hline 9 & Perform lateral tilt (easy patient handling) & 9 & \# of steps for Assembly & 29 & Geometry/Shape of Bed Stage \\
\hline 10 & Require small maintenance frequency & 10 & Handling Height & 30 & Material Tensile Strength \\
\hline 11 & High resistance & 11 & Tolerances & 31 & Material Yield Stress \\
\hline 12 & Change bed height & 12 & Height Adjustment Mechanism & 32 & Surface Finishing \\
\hline 13 & Adjustable bed length & 13 & Backrest Adj. Mechanism & 33 & Material Specific Mass \\
\hline 14 & Food tray & 14 & Thigh-rest Adj. Mechanism & & \\
\hline 15 & Allow self-adjustment of bed & 15 & Footrest Adj. Mechanism & & \\
\hline 16 & Allow more humanized in-bed restraint & 16 & Longitudinal Angular Mech. & & \\
\hline 17 & Have safe adjustment movements & 17 & Lateral Angular Mechanism & & \\
\hline 18 & Good cost-effectiveness ratio & 18 & Movement Transfer Mechanism & & \\
\hline 19 & Reduce risk of forgetting side trails down & 19 & Bed Transportation Mechanism & & \\
\hline 20 & Prevent bedsores & 20 & Side trail Adj. Mechanism & & \\
\hline
\end{tabular}

Table 4. Subliminal Aspects.

\begin{tabular}{|l|l|}
\hline \multicolumn{1}{|c|}{ Reports } & \multicolumn{1}{c|}{ Subliminal Aspects } \\
\hline $\begin{array}{l}\text { Doctors reported that attempts of headboard emergency removal } \\
\text { failed during neck-and-head procedures. }\end{array}$ & $\begin{array}{l}\text { Traditionally, a bed includes a headboard but, for medical purposes, it } \\
\text { may be an obstacle. Then, headboard presence is rethought. }\end{array}$ \\
\hline $\begin{array}{l}\text { The majority of users focused on how good electric beds are. Even } \\
\text { when back to subject, they insisted recalling the automated beds. }\end{array}$ & $\begin{array}{l}\text { Initially, this "out of subject" insistence was neglected, but later } \\
\text { recognized as a requirement to mimic the automated experience. }\end{array}$ \\
\hline $\begin{array}{l}\text { Nurses reported difficulty in changing patient decubitus, even with } \\
\text { electric beds, since another nurse has to be called to control the rolling } \\
\text { of patient body. }\end{array}$ & $\begin{array}{l}\text { It was noticed that all actuators seen are not near patient body. } \\
\text { Decubital actuator needs to be near the patient, for safety and } \\
\text { readiness. }\end{array}$ \\
\hline $\begin{array}{l}\text { Patient company reported improvised adaptation to the thigh-rest board } \\
\text { of the bed due to patient atrophy and loss of bone mass. }\end{array}$ & $\begin{array}{l}\text { Incorporate thigh-rest board length adjustment to enable the bed } \\
\text { for all statures. }\end{array}$ \\
\hline $\begin{array}{l}\text { A patient company about hand-crank beds: "I had to stay there } \\
\text { spinning the crank". }\end{array}$ & $\begin{array}{l}\text { The words "had" and "there" emphasize long time at an uncomfortable } \\
\text { position. Body and facial expressions were pejorative. Manual bed } \\
\text { must become ergonomic. }\end{array}$ \\
\hline $\begin{array}{l}\text { All beds of a public emergency center were electric, but were all } \\
\text { inoperative or improvised for 8 years, due to limited governmental } \\
\text { budget. }\end{array}$ & $\begin{array}{l}\text { lectric bed maintenance is way more expensive than mechanical ones, } \\
\text { reinforcing this project importance and marketing issues. }\end{array}$ \\
\hline
\end{tabular}




\section{Responses per area}

(Total of 101 responses)

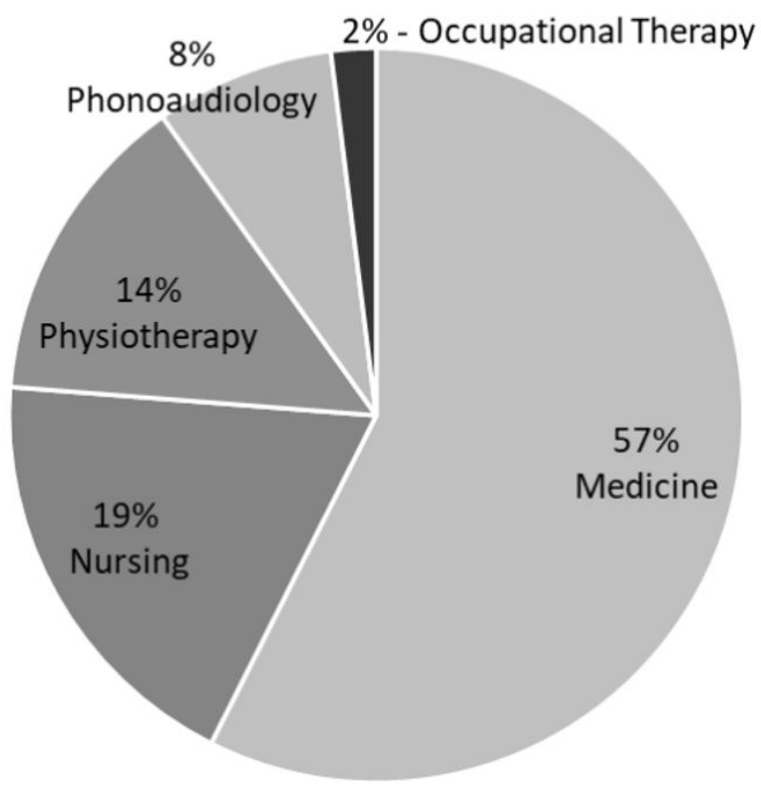

Figure 3. Voice of Customer assessment: questionnaire details. (see Table 3). The aspects on Table 4 need special attention due to their non-obviousness and the concern to unveil them.

In order to evaluate the relevance of the obtained data, QFD tools were used. For the customer requirement assessment, an online quantitative questionnaire was elaborated using a Likert scale, imposing financial tradeoffs for each question. For reliability reasons, the questionnaire was elaborated using recommendations from Hill \& Hill (2008) and only responses submitted by healthcare professionals were considered, accounting 101 effective responses, as detailed in Figure 3. The questionnaire evaluated only a few requirements (presented on Table 5), once mandatory or obvious requirements could turn the assessment unfair (Hill \& Hill, 2008). For simplification purposes, the average grades were rounded. These results are detailed in Table 5 . For the product specification assessment, the Quality Matrix is shown in Table 6, where the bottom row shows the resulted specification ranking. Mandatory or obvious requirements received a relevance grade of 5.0 (highlighted in the matrix). Indexes in Table 5 and Table 6 correlate to the ones on Table 3.

All efforts spent until this stage were done to unveil subliminal aspects and converge into a demand refinement, i.e. what indeed matters for customers. Based on the

Table 5. "Voice of Customer" assessment results.

\begin{tabular}{|l|c|c|c|c|c|c|c|c|c|c|c|c|c|c|c|}
\hline & \multicolumn{10}{|c|}{ Customer Requirements } \\
\cline { 2 - 15 } & $\mathbf{2 0}$ & $\mathbf{1 2}$ & $\mathbf{1 1}$ & $\mathbf{1}$ & $\mathbf{8}$ & $\mathbf{1 6}$ & $\mathbf{2}$ & $\mathbf{9}$ & $\mathbf{7}$ & $\mathbf{1 5}$ & $\mathbf{5}$ & $\mathbf{6}$ & $\mathbf{1 3}$ & $\mathbf{4}$ & $\mathbf{1 4}$ \\
\hline Average Grade & 4.88 & 4.82 & 4.70 & 4.63 & 4.32 & 4.27 & 4.16 & 4.12 & 4.03 & 4.01 & 3.87 & 3.79 & 3.75 & 3.62 & 3.45 \\
\hline Rounded Grade & \multicolumn{1}{|c|}{5.0} & \multicolumn{10}{|c|}{4.5} & \multicolumn{10}{|c|}{4.0} \\
\hline
\end{tabular}

Table 6. Quality Matrix. Note: the resulted weights at the bottom row were rounded.

\begin{tabular}{|c|c|c|c|c|c|c|c|c|c|c|c|c|c|c|c|c|c|c|c|c|c|c|c|c|c|c|c|c|c|c|c|c|c|c|c|}
\hline & \multicolumn{33}{|c|}{ Product Specifications } & \multirow{2}{*}{ Еँ } \\
\hline & & 1 & 2 & 3 & 4 & 5 & 6 & 7 & 8 & 9 & 10 & 11 & 12 & 13 & 14 & 15 & 16 & 17 & 18 & 19 & 20 & 21 & 22 & 23 & 24 & 25 & 26 & 27 & 28 & 29 & 30 & 31 & 32 & 33 & \\
\hline \multirow{20}{*}{ 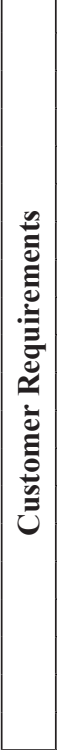 } & 1 & 9 & 9 & 9 & 9 & 9 & 9 & 9 & 9 & 3 & 3 & & & 9 & 9 & 9 & & & & & & & 3 & & & 3 & & & & 9 & 9 & & & 3 & 4.5 \\
\hline & 2 & 9 & 9 & 9 & 9 & 9 & 9 & 9 & 9 & 3 & 3 & & & & & & 9 & & & & & & & & & 1 & & & & 9 & 9 & & & 3 & 4.0 \\
\hline & 3 & & 9 & 3 & & 9 & 9 & 3 & 9 & & 9 & & 9 & 9 & 9 & 9 & 9 & 9 & 9 & & 9 & 9 & 9 & & 9 & & & & & 9 & & & & 3 & 5.0 \\
\hline & 4 & & 3 & 3 & & 3 & 9 & 3 & 9 & & 1 & & 9 & 9 & 9 & 9 & 9 & 9 & 9 & & 9 & 9 & 9 & & & & 1 & 1 & 1 & 1 & & & & 3 & 3.5 \\
\hline & 5 & & 9 & 3 & & 3 & 1 & & & & 9 & & & & & & & & 9 & & 9 & 9 & 9 & 9 & & & & & & & & & & & 4.0 \\
\hline & 6 & 1 & & 1 & & & & & & & & 1 & & 9 & & & 9 & & & & & & & & & & & & & 3 & & & & & 4.0 \\
\hline & 7 & & 3 & 1 & 3 & 9 & & & 3 & 3 & 1 & & & & & & & & & 9 & & & & & 9 & & & 1 & & & & & & & 4.0 \\
\hline & 8 & 9 & 9 & 1 & 1 & 9 & 9 & 9 & 9 & & 9 & & & & & & 9 & & 9 & 9 & & 9 & & & 9 & & & 9 & & & & & & 9 & 4.5 \\
\hline & 9 & 9 & 9 & 1 & 1 & 9 & 9 & 9 & 9 & & \begin{tabular}{|l|}
9 \\
\end{tabular} & & & & & & & & \begin{tabular}{|l|}
9 \\
\end{tabular} & \begin{tabular}{|l|}
9 \\
\end{tabular} & 9 & 9 & 9 & 3 & 9 & & 9 & 9 & 9 & 9 & & & & 9 & 4.0 \\
\hline & 10 & 3 & 1 & 9 & 1 & 3 & & & & & & & 1 & 1 & 1 & 1 & 1 & 1 & 1 & 1 & 1 & 1 & 1 & 1 & 1 & 1 & 1 & 1 & 1 & 1 & 9 & 9 & 9 & & 5.0 \\
\hline & 11 & 3 & 1 & 9 & 1 & 3 & & & & & & & 1 & 1 & 1 & 1 & 1 & 1 & 1 & 1 & 1 & 1 & 1 & 1 & 1 & 1 & 1 & 1 & 1 & 1 & 9 & 9 & 9 & & 4.5 \\
\hline & 12 & & 1 & 3 & & & 1 & 9 & 3 & & & & 9 & & & & & & & & & & & & & & 9 & & & 3 & & & & & 5.0 \\
\hline & 13 & 9 & 9 & 9 & \begin{tabular}{|l|}
9 \\
\end{tabular} & & 1 & 9 & 3 & & & & & 9 & 9 & 9 & & 9 & & & & & 9 & & & & 3 & & & 9 & & & 3 & & 4.0 \\
\hline & 14 & & 3 & 9 & 9 & 1 & 1 & & 3 & & 9 & & 3 & 3 & 1 & 1 & & & & & 9 & & 9 & 9 & & & 1 & & & 9 & & & & 3 & 3.5 \\
\hline & 15 & 3 & 3 & 3 & 1 & 9 & 9 & 3 & 9 & & 9 & & & 9 & 9 & 9 & & & 9 & & & & 9 & 9 & & & 3 & & & 9 & & & 3 & 9 & 4.0 \\
\hline & 16 & & & 1 & & & & & & & & & & & & & & & & & 3 & & & & & 3 & 9 & & & & & & \begin{tabular}{|l}
9 \\
\end{tabular} & & 4.5 \\
\hline & 17 & & & & & 3 & 9 & 1 & 3 & & 3 & & 9 & 9 & 9 & 9 & 9 & 9 & 9 & 9 & 9 & 9 & 9 & 9 & 9 & & 9 & 9 & & 9 & 9 & 9 & 9 & & 5.0 \\
\hline & 18 & 9 & 3 & 9 & 9 & 9 & 1 & 1 & 3 & 3 & 1 & 1 & 3 & 3 & 3 & 3 & 1 & 1 & 9 & 3 & 3 & 1 & 1 & 1 & 3 & 3 & 3 & 1 & 1 & 3 & 9 & 9 & 3 & 3 & 5.0 \\
\hline & 19 & & & 3 & & & & & 3 & & 3 & & & & & & & & & & 9 & & & & & & 9 & & & & & & & & 5.0 \\
\hline & 20 & & & 3 & & & & 9 & & & & & & 9 & 9 & 9 & & 9 & & & & & & & & & & & & 9 & & & & & 5.0 \\
\hline \multicolumn{2}{|c|}{ Weight } & 279 & 345 & 390 & 223 & 385 & 332 & 327 & 360 & 53 & 293 & 9 & 202 & 350 & 307 & 307 & 249 & 217 & 325 & \begin{tabular}{|l|l|}
182 \\
\end{tabular} & 308 & 249 & 325 & 175 & 227 & 56 & 267 & 144 & 54 & 406 & 252 & 176 & 210 & 189 & \\
\hline \multicolumn{2}{|c|}{ Ranking } & 15 & 6 & 2 & 21 & 3 & 7 & 8 & 4 & 32 & 14 & 33 & 24 & 5 & 12 & 12 & 18 & 22 & \begin{tabular}{|l|}
10 \\
\end{tabular} & 26 & 11 & 18 & 9 & 28 & 20 & 30 & 16 & 29 & 31 & 1 & 17 & 27 & \begin{tabular}{|l|}
23 \\
\end{tabular} & 25 & \\
\hline
\end{tabular}


requirement and specification relevance assessments, the refined demand is the following:

A long-lasting manual hospital bed with a good cost-effectiveness ratio, comprising: a bed stage that comfortably performs lateral tilt (preventing bedsores) and the Fowler and Trendelemburg positions for various statures, as well as allows a more humanized in-bed patient restraint; an easy and fast manual actuation that requires small effort and has a comfortable height of actuation, feasible for various statures; safe side trails, avoiding the main hospital bed accidents; and a proper architecture to facilitate medical procedures, mainly in neck-and-head region.

\section{Conceptual project}

From the refined demand, it is possible to start the conceptual phase. Since the engineering product development follows the product functionality (Ulrich \& Eppinger, 1995), the above refined demand will be considered as the manual hospital bed main function.

\subsection{Functional decomposition}

The functional decomposition for the manual hospital bed is shown in Figure 4. It is important to note some remarks on Figure 4. The dotted area represents recurrent subfunctions and will be evaluated together in solution generation. The subfunction "store energy" stands for the subliminal requirement "mimic the automated experience", wherein the agent can perform the work only at the beginning of the task and energy will be kept for the desired bed adjustment. The headboard and footboard were removed from the current proposal, once they may represent obstacles in medical assistance and operation, yet not offering any other safety function.

\subsection{Solution generation following function}

The second step of this conceptual project consists in generating solutions for each of the subfunctions earlier stated. Indeed, as mentioned before, Figure 1 and Figure 2 were used as supportive tools to generate ideas, which were organized in groups per subfunction in the morphological matrix, shown in Figure 5 and Figure 6. To later assist the product architecture, a feature was added in each icon's upper-right corners: a shortcut description for the types of the input and output movements. For example: "T $>$ R" means that a translational input movement $(\mathrm{T})$ turns into a rotational output movement $(\mathrm{R})$.

\subsection{Concept selection}

The concept selection is done from the combination of possible solutions, leading to a huge number of generated concepts $-28,800,000$ possibilities. Then, the design team has to narrow down the number of solutions based on technical background knowledge (Ulrich \& Eppinger, 1995). At this stage, convergent thinking and engineering approaches are welcome. In Figure 5 and Figure 6, the circled solutions represent the decisions from technical analysis,
Functions

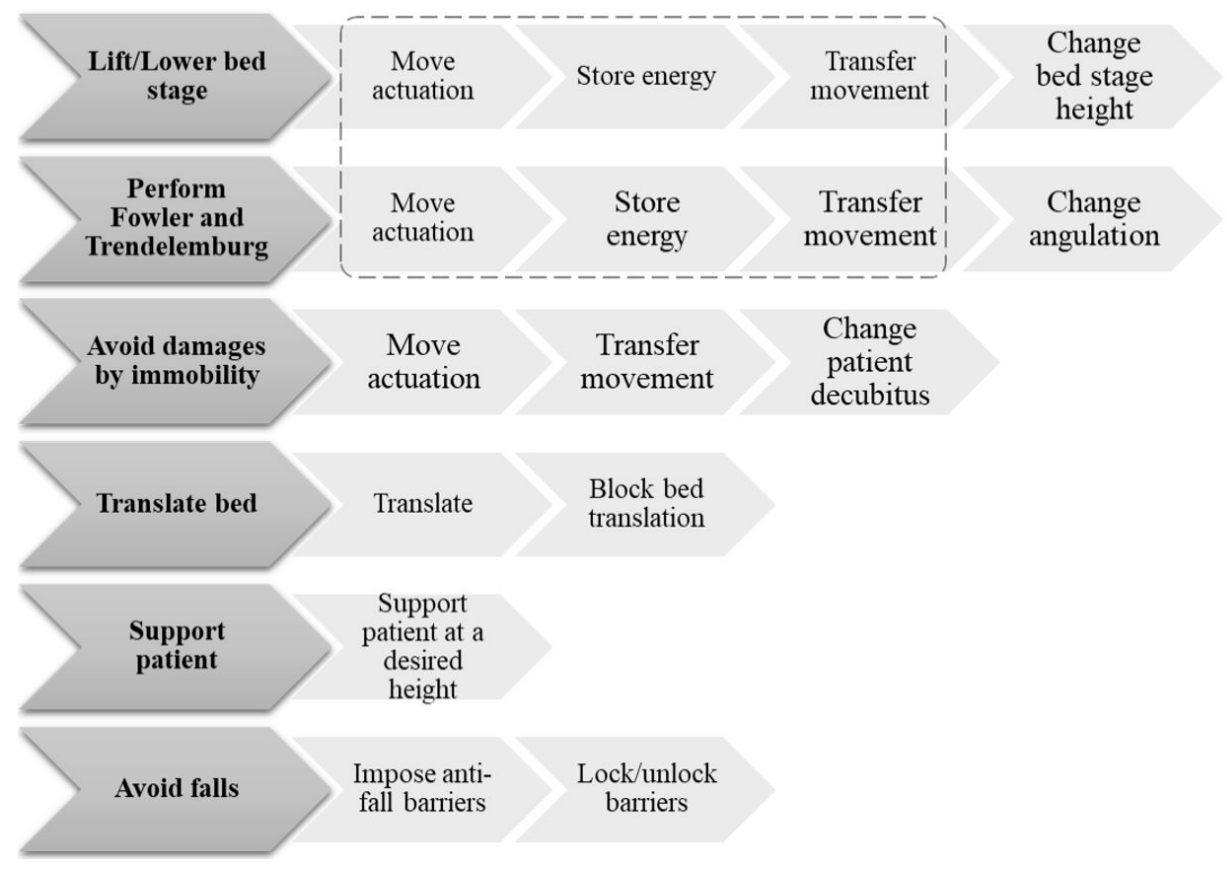

Figure 4. Functional decomposition. 
whose main guidance was the refined demand principles. The most relevant decisions are following explained.

For safety reasons, the manual hospital bed shall not be independently responsible for the "Change patient decubitus" task. The healthcare professional should guide and take complete control of the patient body during this task. Therefore, the "Lever" was chosen due to a possible proximity to patient body, while requiring small actuation force owed to the torque balance. "Spring" option was rejected for safety reasons, regarding its abrupt energy release. "Drive screw" was selected, once it can be designed to be self-locking (Budynas \& Nisbett, 2016). In "Change angulation", only "Mechanism 3" and "Mechanism 4" are compatible in type of movement (translation from "Drive Screw"), but, in "Mechanism 4", the load vertical component is completely supported by the manual actuation, which is not ergonomic. Once the knee joint is the only constraint for different stature comfortable accommodation, the "Extensible Thigh Rest" is the most appropriate and stable solution among the others ("Flexible Support" seems to be a great idea to try an organic patient accommodation, but it deserves specific attention on a separate design project). The first design feature attempted was the "Pedal" for an ergonomic manual actuation. However, because of

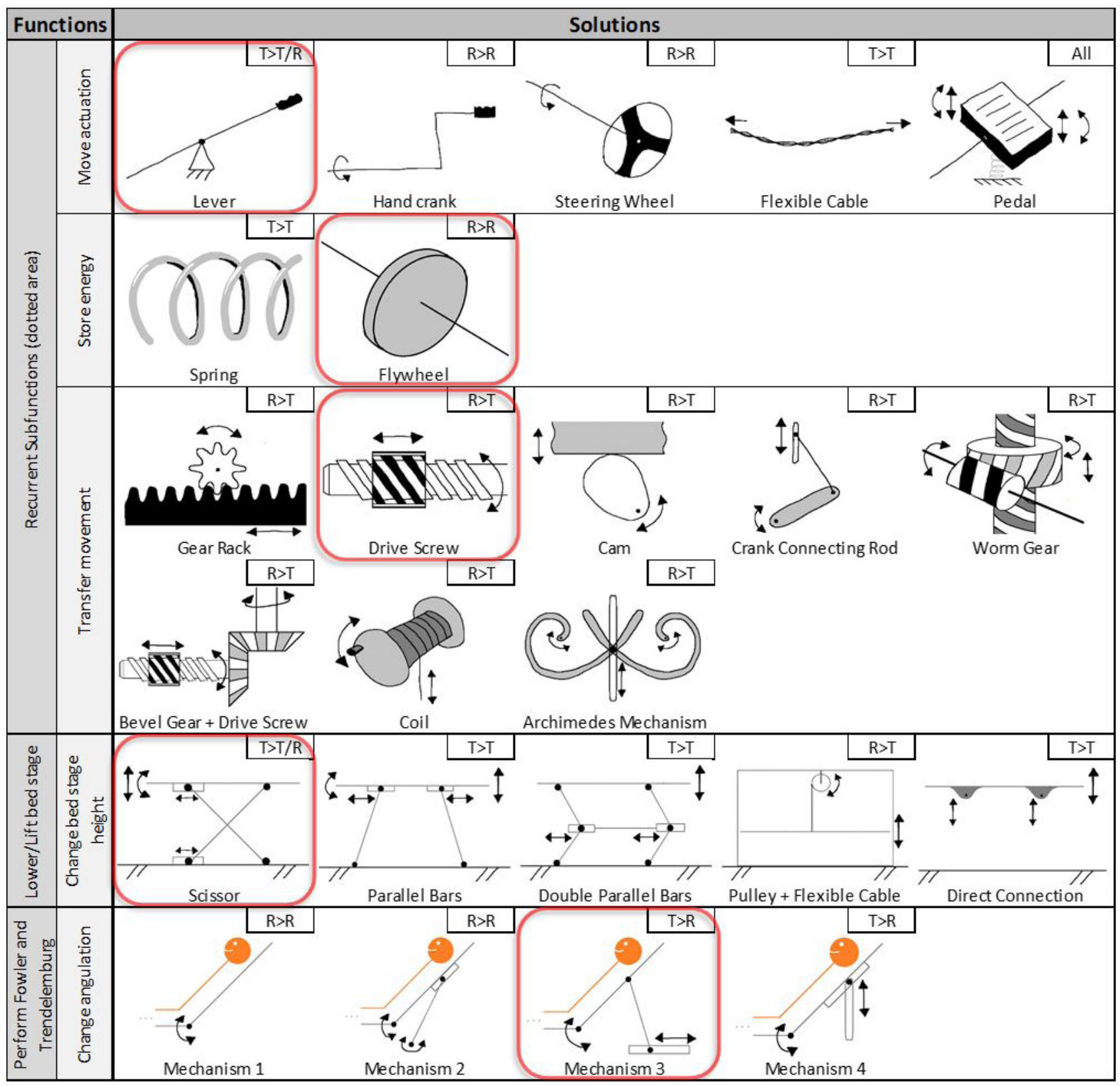

Figure 5. Morphological Matrix - part 1. 


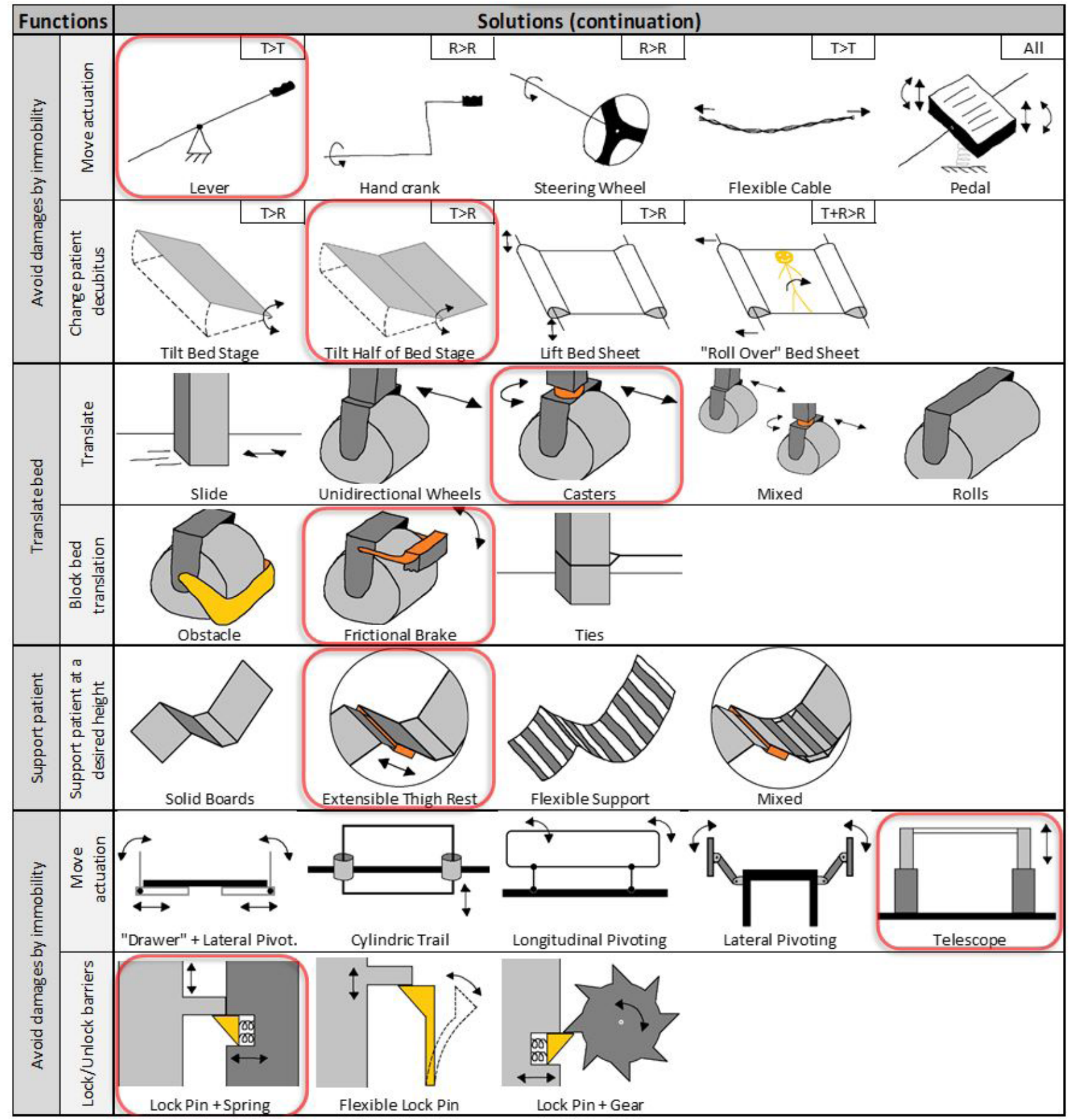

Figure 6. Morphological Matrix - part 2.

complexity of rotating the drive screw in both ways and adjusting the bed height hindered by rigid elements, this feature was considered too complex to assure feasibility. The choice for "Change bed stage height" was "Scissor" due to its triangulated structure stability.

\section{Product architecture and results}

Finally, this step represents the product embodiment, when the solutions have to be connected. This task may be tough and recursive, leading the design team to go back and forth in the decisions. The manual hospital bed architecture is summarized by its main systems.

\subsection{Manual actuation system}

It consists in the interface between the actuating user and the bed mechanism. The whole actuation system is composed of three sets of components: ratcheted levers, flywheels and contact-pin shafts, which are secured inside a cage (Figure 7). 


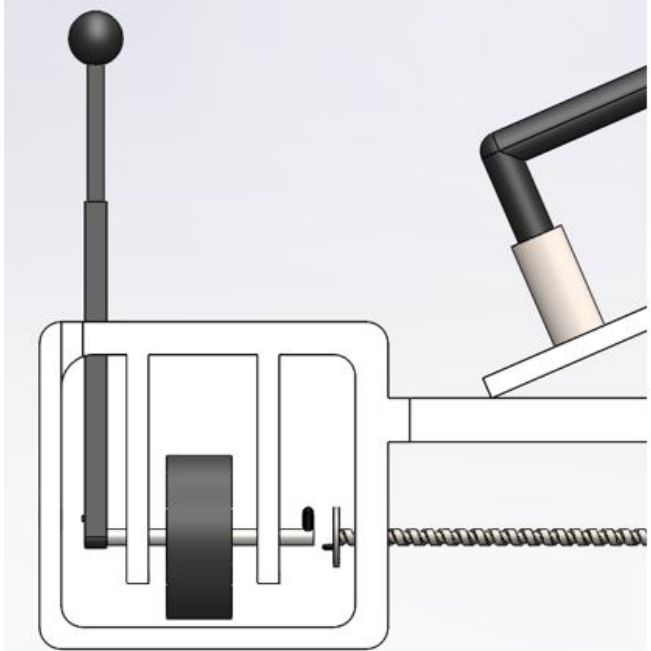

Figure 7. Actuation system.

For adjustment of bed height, backrest and thigh-rest angulations, three levers were designed to be telescopic, providing a more ergonomic work by extending their size. The levers are ratcheted and connected to shafts with the purpose to spin them by repetitive impulses. Since the spinning must be allowed in both ways, the ratchet is reversible, whose pointer (Figure 8) will indicate whether lifting or lowering is desired. Another function incorporated to the levers is the coupling of mechanisms, when the desired bed movement is set to start. That is, after transferring rotational energy to the connected flywheel, the user will push the lever forward through a cage channel (Figure 9) to activate the desired bed movement. To stop it, the user must pull the lever back to initial position. Details will be clarified along the text.

This manual operation version brings more comfort and practicality. With the usual hand cranks, the user had to stay down until the bed movement was completed, but with this proposal, the user never stays at an uncomfortable position, nor even perform work during the whole adjustment task. It is inspired by the vehicle gear shift to mimic the desired automated experience.

\subsection{Energy storage system}

Through flywheels (Figure 10), the rotational kinetic energy is stored, allowing the user to perform work only at the beginning of the task.

\subsection{Movement transfer system}

The rotational movement will be actually transferred to the bed when two pins get in contact by the moment the lever is pushed forward (Figure 11 and Figure 12). Figure 7 helps visualization of this movement. The pins must be made of a resilient material. Indeed, a negative point may be the collision shock, which could be solved with a clutch

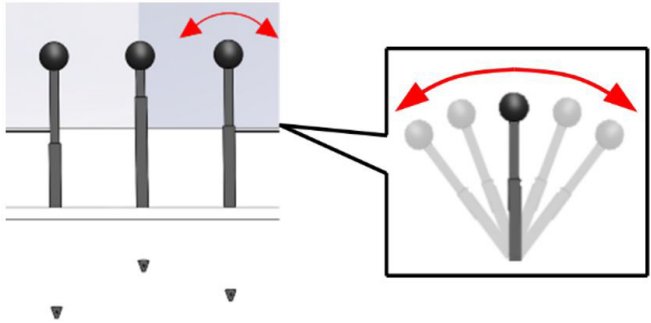

Figure 8. Ratchet reversible pointer.

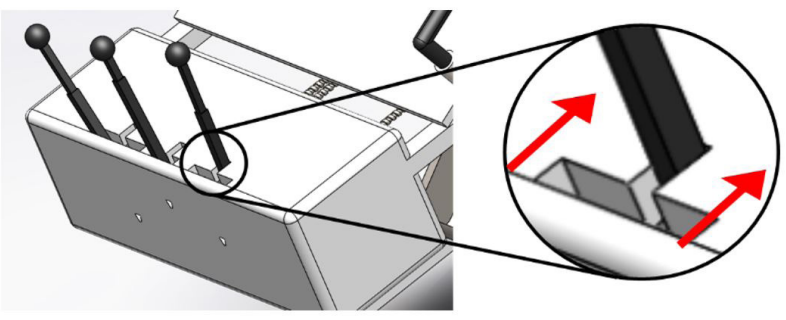

Figure 9. Cage channel.

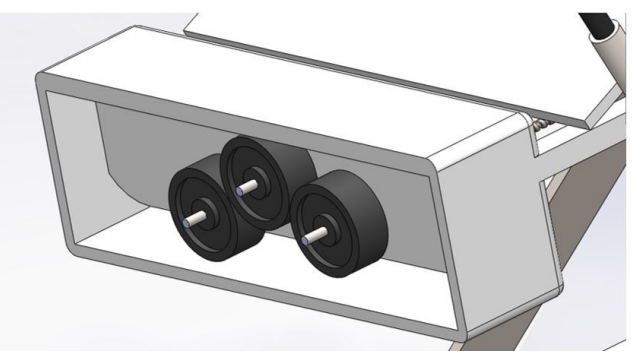

Figure 10. Flywheels.
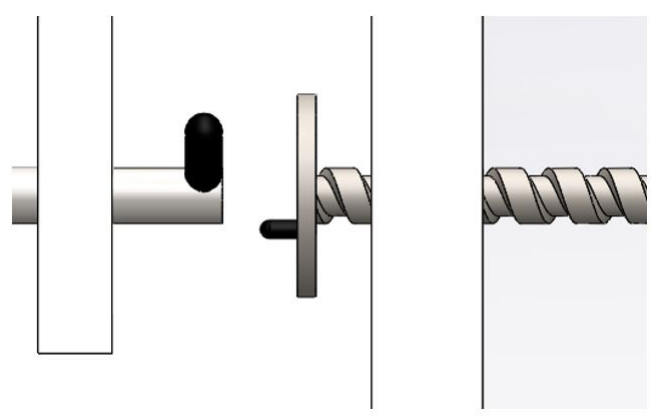

Figure 11. Pins before connection.
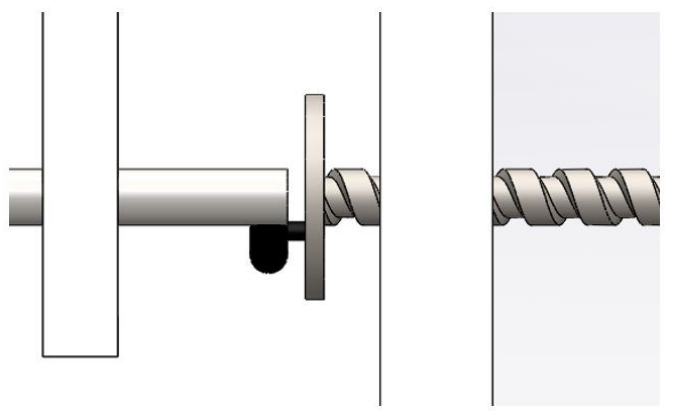

Figure 12. Connected pins. 


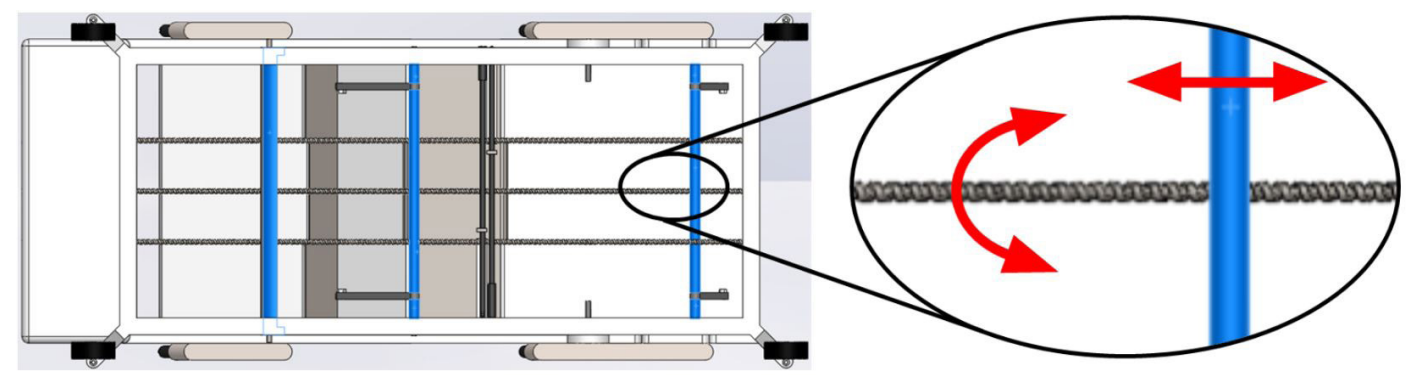

Figure 13. Bottom view: threaded connections.

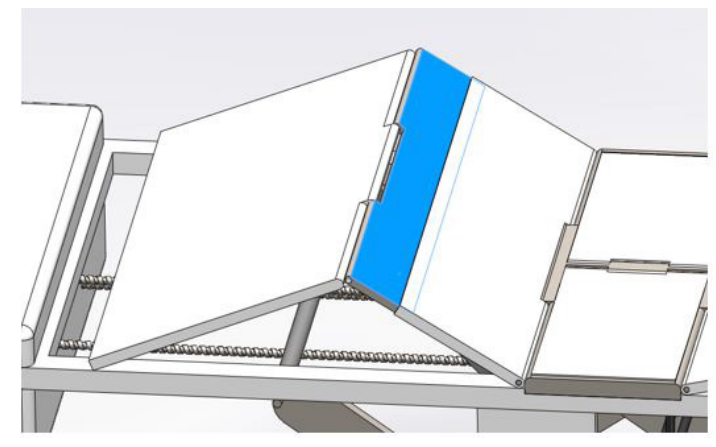

Figure 14. Thigh Rest extended.

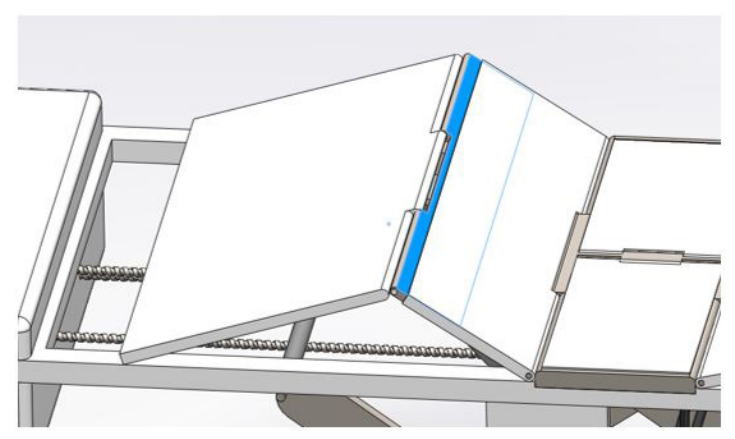

Figure 15. Thigh Rest retracted.

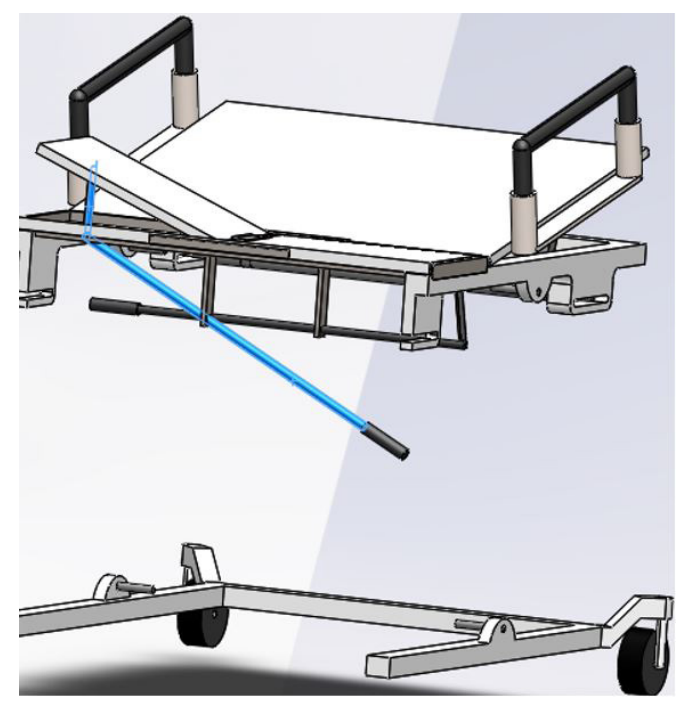

Figure 16. Board-leveraging mechanism. mechanism, but these options would have to be simulated in a specific and appropriate study. When the pin contact occurs, the respective drive screw spins and provides translation to a threaded connection (Figure 13), which will move the bottom of an intermediate support beam, lifting or lowering the bed boards.

\subsection{Thigh-rest retraction system}

To accommodate patients with a varied range of stature, a retractable thigh-rest board was designed inspired by drawers (Figure 14 and Figure 15). When the patient is lying on horizontal position, the healthcare professional can align the thigh-rest joint to the patient knees.

\subsection{Decubital change system}

The patient decubital change will be aided by a board-leveraging mechanism. As shown in Figure 16, a small load will be required from the healthcare professional due to the lever arm. Also, the task will be done near to the patient body, allowing more control, safety and autonomy for a single professional. The seat board was chosen to receive this mechanism because it is always horizontal and is near to the human body center of mass.

\section{Discussion and conclusion}

The final concept proposal is represented in Figure 17. It provides innovative features that enhance the customer experience, compensating manual adjustment efforts. The proposal, which can be clearly industrialized, keeps the affordability advantage of the typical manual hospital beds. Note that, although a more humanized in-bed patient restraint seems to be an important factor, it was not further discussed in this paper because proposals would have to involve many other fields of study. Also, the Trendelemburg position was not incorporated to the final concept once it is not mandatory for a generic hospital bed and would add more complexity to the product, increasing its cost. For future studies, the upcoming life-cycle project phases may be executed, mainly concerning the testing and reconsideration of the pin proposal for the transfer movement system. 


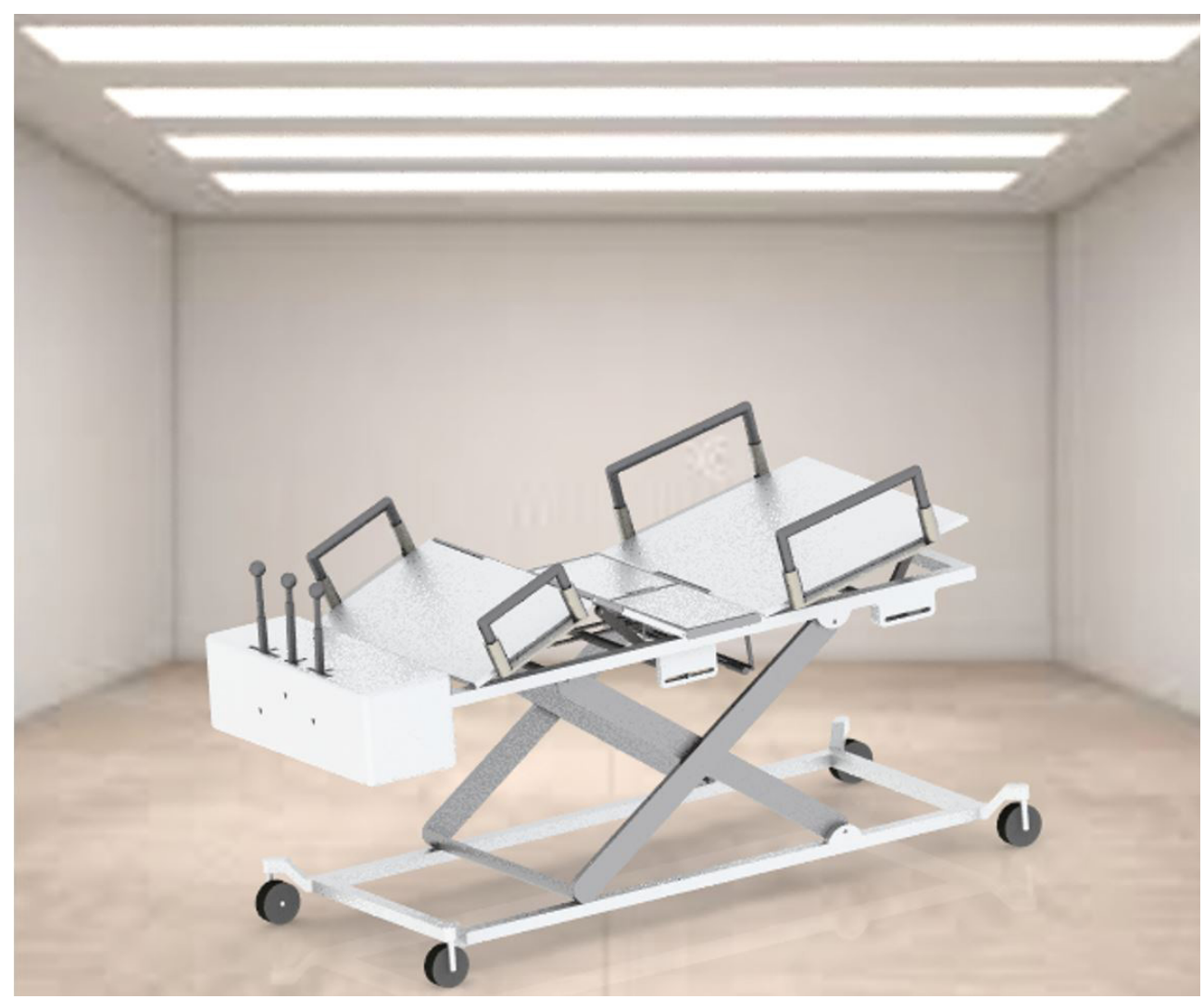

Figure 17. Final concept proposal for the manually adjustable hospital bed.

\section{Acknowledgements}

The authors thank each individual who made the visits possible, volunteered to interviews, answered the online questionnaire and provided constant feedback.

\section{References}

Alexandre, N. M., \& Rogante, M. M. (2000). Movimentação e transferência de pacientes: aspectos posturais e ergonômicos. Revista da Escola de Enfermagem da USP, 34(2), 165-173. http://dx.doi.org/10.1590/S0080-62342000000200006.

Associação Brasileira de Normas Técnicas - ABNT. (2013). ABNT NBR IEC 60601-2-52 - Equipamento eletromédico Parte 2-52: Requisitos particulares para a segurança básica e o desempenho essencial das camas hospitalares. Retrieved in 2018, July 1, from http://www.abnt.org.br/

Bond Hospitalar. (2018). Retrieved in 2018, April 1, from https://www.grupobond.com

Brasil. Agência Nacional de Vigilância Sanitária - ANVISA. (2017). Manual para Regularização de Equipamentos Médicos na ANVISA. Brasília: ANVISA. Retrieved in 2018, June 1, from http://portal.anvisa.gov.br

Brasil. Ministério da Saúde. Agência Nacional de Vigilância Sanitária - ANVISA. (2013). Anexo 02: protocolo para prevenção de úlcera por pressão. Brasília: Ministério da Saúde. Retrieved in 2018, May 1, from https://www.anvisa. gov.br

Budynas, R. G., \& Nisbett, J. K. (2016). Elementos de Máquina de Shigley (10th ed.). Porto Alegre: McGraw Hill Brasil.

Cheng, L. C., \& Melo Filho, L. D. (2010). QFD-Desdobramento da Função Qualidade na Gestão de Desenvolvimento de Produtos (2. ed.). São Paulo: Blucher.

Correa, C. L., \& Waldow, V. R. (1982). Atendimento à necessidade básica de conforto a pacientes acamados. Revista Gaúcha de Enfermagem, 3(2), 111-117.

Diccini, S., Pinho, P. G., \& Silva, F. O. (2008). Avaliação de risco e incidência de queda em pacientes neurocirúrgicos. Revista Latino-Americana de Enfermagem, 16(4), 752-757. http://dx.doi.org/10.1590/S0104-11692008000400016

Gomide, D. A., Shinkawa, D. Y., Rodrigues, T. J., Alkindi, A.K. I., \& Lima Filho, A. D. (2015). Cama Hospitalar Especial. In Anais do $8^{\circ}$ Congresso de Extensão Universitária da UNESP. Ilha Solteira: UNESP.

Hill, M. M., \& Hill, A. (2008). Investigação por questionário. Lisboa: Edições Sílabo. 
Instituto Nacional da Propriedade Intelectual - INPI. (2018). Patentes. Retrieved in 2018, April 1, from http://antigo. inpi.gov.br/

Laguna-Parras, J. M., Arrabal-Orpez, M. J., Zafra-López, F., García-Fernández, F. P., Carrascosa-Corral, R. R., Carrascosa-García, M. I., Luque-Martínez, F. M., AlejoEsteban, J. A. (2011). Incidencia de caídas en un hospital de nivel 1: factores relacionados. Gerokomos - Revista Oficial de la Sociedad Española de Enfermería Geriátrica y Gerontológica, 22(4), 167-173. http://dx.doi.org/10.4321/ S1134-928X2011000400004

Malça, C., \& Beirão, P. (2010). Aplicação de um Sistema Sanitário a Camas Hospitalares: Módulo Rotativo. TechnoHospital, 39, 24-30. Retrieved in 2018, May 1, from http://www.tecnohospital.pt

Metahospitalar. (2018). Retrieved in 2018, April 1, from http:// www.metahospitalar.com.br

Missio, C., \& Mazzini Junior, E. (2016). Projeto de cama hospitalar regulável por manivela manual. Revista Eletrônica Disciplinarum: Ciências Naturais e Tecnológicas, Naturais e Tecnológicas, 17(1), 99-117.

Naveiro, R. M., \& Oliveira, V. M. (2018). QFD and TRIZ integration in product development: a model for systematic optimization of engineering requirements. Production, 28(e20170093). http://dx.doi.org/10.1590/01036513.20170093 .

Ortopedia Portugal. (2018). Retrieved in 2018, April 1, from https://www.ortopediaportugal.pt
Rodrigues, L. H., Barela, J., Costa, W. B., Paschoarelli, L. C., \& Silva, J. C. (2013). Problemas Ergonômicos Enfrentados por Profissionais de Enfermagem em Ambientes Hospitalares: Aspectos da Interface Trabalhadores x Equipamentos. Caderno de Estudos Tecnológicos - FATEC/BAURU, 1(1), 218-225. Retrieved in 2018, May 1, from http://www. fatecbauru.edu.br

Romeiro Filho, E., Ferreira, C. V., Miguel, P. A., Gouvinhas, R. P., \& Naveiro, R. M. (2009). Projeto do produto. São Paulo: Elsevier.

Silva Júnior, A. J. (2003). Cama Hospitalar: Desenvolvimento de uma Alternativa para a Internação Domiciliar [Dissertação de Mestrado]. Universidade do Vale do Paraíba, São José dos Campos.

Ullman, D. G. (1992). The mechanical design process. New York: McGraw-Hill.

Ulrich, K. T., \& Eppinger, S. D. (1995). Product design and development. New York: McGraw-Hill.

United States Patent and Trademark Office - USPTO. (2018). USPTO Patent Full-Text and Image Database (PatFT). Retrieved in 2018, April 1, from https://www.uspto.gov/

Victorelli, G., Ramacciato, J. C., Andrade, E. D., Ranali, J., \& Motta, R. H. (2013). Suporte Básico de Vida e Ressuscitação Cardiopulmonar em adultos: conceitos atuais e novas recomendações. Revista da Associacao Paulista de Cirurgioes Dentistas, 67(2), 124-128. 